Meta

Journal des traducteurs

Translators' Journal

\title{
Bilingual Speakers as Informants in a Comparative Lexical Semantic Analysis
}

\section{Christine Bagge}

Volume 35, numéro 2, juin 1990

URI : https://id.erudit.org/iderudit/001947ar

DOI : https://doi.org/10.7202/001947ar

Aller au sommaire du numéro

Éditeur(s)

Les Presses de l'Université de Montréal

ISSN

0026-0452 (imprimé)

1492-1421 (numérique)

Découvrir la revue

Citer cet article

Bagge, C. (1990). Bilingual Speakers as Informants in a Comparative Lexical Semantic Analysis. Meta, 35(2), 414-416. https://doi.org/10.7202/001947ar d'utilisation que vous pouvez consulter en ligne.

https://apropos.erudit.org/fr/usagers/politique-dutilisation/ 


\section{BILINGUAL SPEAKERS AS INFORMANTS IN A COMPARATIVE LEXICAL SEMANTIC ANALYSIS}

\section{INTRODUCTION: LANGUAGE IN A CONTRASTIVE LEXICAL ANALYSIS}

Linguistics is the scientific study of human language. Its field of enquiry is therefore vast and complex, and by its nature it necessitates a number of highly specialised sub-fields of investigation. In very broad terms language can be defined as a special mode of communication, languages "constituting a species of the genus communication system" (Harris 1980: 21-22). The behaviourist psycholinguist, however, will view it as a behaviour, the sociolinguist as a social institution, the grammarian as an abstract system. The lexicologist, for his part, only considers the fact that languages are made up of words. From his perspective, language is analysed in terms of its vocabulary. One essential characteristic of the vocabulary of any living language is its dynamism as reflected in the frequent creation of neologisms. Indeed, it is the open-ended aspect of vocabulary sets which necessitates the constant updating of dictionaries and even the publication of dictionaries of neologisms. The lexicologist, however, has to delineate the boundaries of his enquiry and considers language as a finite set of words; it is finite at a certain point in time. The corpus of a bilingual lexical comparison will then be constituted by the sets of words of the two languages considered. For practical purposes, this corpus can be defined as the two sets of words listed by the standard monolingual dictionaries of each language. If the lexicologist is also a semanticist, he will concern himself not only with the meanings of individual words, but also with the relationships existing between word-meanings - i.e. synonymy, polysemy, homonymy and hyponymy in the case of an interlingual analysis; equivalence if more than one language is under description.

In addition to choosing a specific perspective, the linguist also narrows down his field $^{1}$ by concentrating on particular cases of the general phenomenon of language, that is on individual languages. He works on the assumption that many basic facts about one language have exact parallels in other languages. Very pervasive similarities between languages, especially historically related languages, encourage him to believe that it is possible to make some very general statements about all languages. A bilingual lexical semantic analysis, however, will not have as an ultimate goal the circumscription of what language is: it will not lead to generalisations about language. The generalisations it will generate are designed to apply only to the vocabularies of the two languages under description.

\section{INFORMANTS IN A CONTRASTIVE LEXICAL ANALYSIS}

Once the lexicologist has narrowed down his ${ }^{1}$ object of investigation, he needs to evaluate what he has at his disposal in order to carry out his inquiry. He will take it for granted that the meanings of the words in a language can be considered as known to competent speakers of the language: for if the latter did not know the meanings of the words they use, then it would be difficult to see how they succeed in communicating so frequently. Native speakers of the languages are the primary source of information about meaning. Consequently, the lexicologist comparing the meanings of the vocabularies of two languages, L1 and L2, will be able to call upon two sets of informants: the speakers of L1 and the speakers of L2. A third population will also be helpful to him in his investigation - a bilingual population, the speakers of both $\mathrm{L} 1$ and $\mathrm{L} 2$. In a lexical context, speaking both L1 and L2 does not imply the union of two abstract concepts such as two different behaviours (see introduction above). For the purposes of a comparative lexical analysis, it will simply mean that the bilingual possesses a wider vocabulary, a set of 
words $\mathrm{V}$ that will include the set $\mathrm{V} 1$ contained in $\mathrm{L} 1$ and the set $\mathrm{V} 2$ contained in $\mathrm{L} 2$. Relying on bilingual speakers requires that a speech community using $\mathrm{V}$ actually exists. There is no doubt that such communities can be found. In fact, according to Fishman (1967) more than half of the world's population today uses more than one language while engaging in the activities basic to human needs. It does not imply that all possible combinations of $V$ exists, but if L1 is English and L2 French, the vocabulary users of V form a community widely spread. To mention but one example, vocabulary users of $V$ constitute an important percentage of the language users in Canada. A great number of historical and sociological reasons account for the existence of these bilingual communities, but these explanations lie outside the scope of this argument. It is then clear that in the context of a bilingual lexical analysis V exists as the union of V1 and V2. However, two main objections could be raised against using bilingual speakers as informants.

First, they are not as easily identifiable as speakers of L1 and L2. According to Bloomfield (1933: 56), bilingualism means "a native-like control of two languages". A "true" bilingual, often referred to as an equilingual, is someone who at all times is taken for a native by native speakers of both the languages concerned (Thiery 1976). Bilinguals, however, possess different degrees of bilingualism. They can be ranged from the rare equilingual at one end of the spectrum to the person who has begun to acquire a second language at the other end. The lexicologist is not interested in the bilingual's degree of bilingualism in the four skills traditionally tested: aural comprehension, oral expression, reading comprehension and writing. What he requires of the bilingual is that he has an intuitive grasp of the meanings of the words. For this reason, he will choose vacabulary users of $\mathrm{V}$ who possess what is usually called "infant bilingualism". This term is used when bilingualism is the first language, to use Swain's expression (Swain 1972: Bilingualism as a First Language), in situations where both languages are acquired simultaneously from birth and neither is ever abandoned. Those who have learned the two languages successively as children, i.e. who possess "child bilingualism" will also be used. Both these types of bilinguals qualify as reliable informants: that is to say, they are at least as reliable as native speakers of one language. The "ideal language user" who would know his language (or languages) perfectly does not exist.

The second objection that could be raised against using bilinguals as informants lies in the fact few of them manage to avoid transference. The term "transference" is used by Clyne (1967) to refer to the transferring by bilinguals of elements of one language into another. Transference may be of various types of which two will be relevant to a contrastive lexical analysis: lexical transference and lexical semantic transference. An example of lexical transference would be the following utterance: "I have put away all my toys in the malle". Far from being a handicap, this kind of transference could be seen as evidence that on the lexical level bilingual speakers do experience V1 and V2 as an extension of one another, as a union. Lexical semantic transference is a much more serious issue, since it consists in extending the meaning of a word in $\mathrm{L} 1$ to a word in $\mathrm{L} 2$. It is a problem inasmuch as what is under scrutiny in a contrastive semantic analysis of words is not the bilingual's actual use of language in everyday life but a comparison of two vocabularies belonging to two clearly distinct languages. However, although this phenomenon undoubtedly occurs in conversational situations, it is unlikely to do so when the meaning of a word is consciously described. It is a well-known fact that when questioned about language informants automatically revert to the norm, that is the form of the language which reflects average common use and is considered most often as obeying the rules. The contradictions that exist between introspective judgements and behaviour have been empirically measured by Labov (1975). Notably, he investigated the reactions of speakers to the positive "anymore" dialect in five different regions of the United States. In the 
Midwest, where this dialect is common, "anymore" is used in positive sentences to mean "nowadays". What is relevant to the present argument is that he showed in a scientific way that the people will say one thing and do another. Speakers of the dialect in question denied ever using "anymore" in a positive sense, even when they were simultaneously doing so. Taylor also points out that an informant will label "ungrammatical" the sentence That's the motorbike what I saw "(...) in spite of the fact that he and his friends regularly use what to introduce relative clauses" (Taylor 1981:3). A good example of such a phenomenon in French would be the difference between Je sais pas that most speakers will use and $J e$ ne sais pas that they will only accept as grammatical. In the same way, it can be safely assumed that even if bilingual speakers do not always avoid semantic transference in utterances, they will automatically remove it from the sentences that they are considering in a formal setting. The distinction between langue and parole established by de Saussure (1960:36-38) and restated by Chomsky (1965:4) as the difference between competence and performance did not prevent investigators from using native speakers as informants. Similarly, there is no reason why semantic transference, which is part of parole or performance, should unduly influence the reliability of bilingual speakers as informants when what is under description is the langue.

\section{CONCLUSION}

In his comparison of word-meanings across languages the lexicologist will then have at his disposal three kinds of informants:

(1) speakers of $\mathrm{L} 1$

(2) speakers of L2; and

(3) speakers of both L1 and L2.

It remains now to be established in what way these informants will be utilized since the method used cannot, if it is to be rigorous, merely consist in asking them to decide intuitively whether two given words have or do not have the same meaning. This is the topic of further research which is underway.

CHRISTINE BAGGE Laurentian University, Sudbury, Canada

\section{NOTE}

1. The choice of masculine pronouns in preference to the awkwardness encountered by using "he/she", "his / her", etc., is in no way a sexist statement.

\section{BIBLIOGRAGHY}

BLOOMFIELD, L. (1933): Language, New York: Holt, Rinehart and Winston.

CHOMSKY, N. (1965): Aspects of the Theory of Syntax, Cambridge, Mass.: M.I.T. Press.

CLYNE, M. (1967): Transference and Triggering, The Hague: Nijhoff.

FISHMAN, J. (1967): "Bilingualism, intelligence and language learning", The Modern Language Journal, 44: 227-236.

HARRIS, R. (1980): The Language-Makers, London: Duckworth.

LABOV, W. (1975): What is a Linguistic Fact?, Lisse: The Peter de Ridder Press, $5^{\text {th }}$ ed.

SAUSSURE, F. DE (1960): Cours de linguistique générale, Paris: Payot, $5^{\complement}$ éd.

SWAIN, M. (1972): Bilinguism as a First Language, Ph.D. thesis, University of California at Irvine.

TAYLOR, T. J. (1981): Linguistic Theory and Structural Stylistics, Oxford: Pergamon Press.

THIÉRY, C. (1976), "Le bilinguisme vrai”, Études de linguistique appliquée, 24: 52-63. 